\title{
Opportunities and Challenges of Sporting Goods Manufacturing Industry under the New Retail Mode
}

\author{
Yijun Bai ${ }^{1,2}$, Can Yu ${ }^{3 *}$ \\ ${ }^{1}$ Department of physical education, Luoyang Normal University, Luoyang, China \\ ${ }^{2}$ China Telecom Guangzhou Tianhe Branch, Guangzhou, China \\ ${ }^{3}$ Institute of physical education, Henan Kaifeng Collegeof Science Technology and Communication, Kaifeng, \\ Henan, China \\ *Corresponding Author.
}

\begin{abstract}
By using literature inquiry and logical reasoning methods, this paper studies the definition and characteristics of "new retailing", The current situation and existing problems of sports goods manufacturing industry participating in "new retail" are clarified, and the existing problems are pointed out that under "new retailing" mode, during transition period of sales transformation and stores reformulation, Sporting goods manufacturing industry has no obvious huge advantage, but the opportunities of overtaking opponents at some key points do exist. However, with the advent of the new era, challenges often outweigh opportunities.Sporting goods manufacturing is like other companies, face the pain and change of sales transformation, but this kind of transformation is not a denial and abandonment of the traditional retail system, but a complementation of advantages. Therefore, the retailers of sporting goods manufacturing industry must stand in the perspective of "new retail" from the perspective of customer experience, highly integrate online and offline retaling and logistics, use technologies such as the Internet and big data to influence customers' decision-making and purchasing behavior, and improve their trust in the products. Finally, the paper proposes solutions and suggestions based on the problems existing in the enterprises' involvement in the "new retailing" mode,It provides the basis for the decision-making of sports goods manufacturing industry and management department.
\end{abstract}

Keywords: Big data; "new retailing"; Transformation and upgrading of sporting goods manufacturing industry

\section{Purposes and Significances}

With the application of mobile Internet, big data, cloud computing and other technologies, traditional retail and e-commerce cannot meet the needs of the era development, and a new retailing mode is about to emerge. In 2016, Jack Ma made his "new retailing" for the first time. This new concept quickly swept through physical and Internet retail, attracting the attention and interpretation on him from different industries and different people. "New retailing" is driven by big data, using modern society's information, technology, resources, etc., to upgrade the old "retailing", so that customers have a better product experience, lower purchasing cost, higher product quality and so on, and its core is to improve and optimize consumption patterns. In fact, new retailing is just a concept proposed by Jack Ma. No matter what it is called, not only sales, but also every industry is trying to take advantage of big data and the Internet, because every industry has reached a critical juncture of reform. The sporting goods industry is in no exception. It also faces the situation of poor sales channels and shrinking groups. Sporting goods sellers are also thinking about how to change, how to use the "new retailing" mode, big data, artificial intelligence, and technology to improve user experience and logistics services, increase user purchasing desire under the premise of ensuring product quality, increase sales and profits, maximize sales profits, and promote the development of the sporting goods industry. Under this background, how sporting goods sellers implement the "new retailing" mode, highly integrate online and offline retailing and logistics from the perspective of customer experience, influence customers' purchasing behavior with the applications of Internet, big data and other technologies, has become hot issues in the industry and research field. It is hoped that the research in this paper can help sporting goods sellers to deepen their understanding of "new retailing" and better produce the synergistic effect of "new retailing" sales mode. 


\section{Definition and Basic Characteristics of New Retailing}

\subsection{What is new retailing}

New retailing is a retailing mode that companies, relying on the Internet, using big data analysis, artificial intelligence decision-making and other technical means, comprehensively upgrade product production, circulation and sales process, reshape the structure of the business and the ecosystem, and highly integrate online and offline retailing with modern logistics (see Fig 1).

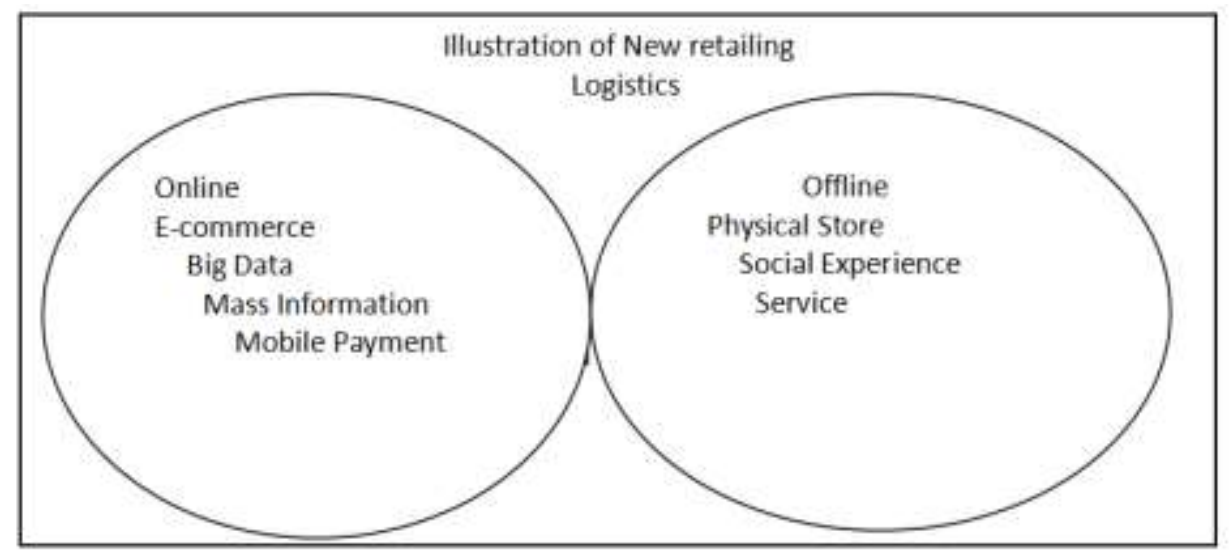

Fig 1. Illustration of New retailing Logistics

\subsection{Basic characteristics of new retailing}

\subsubsection{Online gene + offline gene + logistics}

The core of new retailing is the integration of offline, online retailing and logistics in the retailing industry, and the integration of the three is the future development trend. Both JD.com and Alibaba are developing offline retailing. Not only JD.com develops self-operated logistics, but Taobao is also strengthening the construction of offline self-operated logistics Green Hand and cloud warehouses. At the same time, users have higher and higher requirements for e-commerce products and user experience, and it is difficult for pure e-commerce companies to meet market needs without developing offline retailing. Thus, online and offline resources are shared to integrate inventory, merchandise, logistics and other links. The three must complement each other's advantages and conform to future development trends.

\subsubsection{Deepen customer's omni-channel experience}

For consumers, the experiential consumption of goods before purchasing will be further upgraded. Whether it is PC online stores, mobile apps, WeChat malls or other physical stores, all channels will implement unified prices and real-time inventory. Real-time query, order placing and payment can be done on line, while experiencing and personalized services enjoying can be obtained off line [3]. That is really taking customer needs as the guide to carry out effective marketing.

\subsubsection{Big data precise marketing}

The acquisition, analysis and integration of consumer behavior data online and offline will help retailers better understand consumer needs and provide more precise consumption guidance. With the rapid development of the mobile Internet, the user profile constructed by mobile data is not only complete, but the information transmitted is also richer and more accurate.

\subsubsection{Supply chain reconstruction}

New retailing requires to reconstruct the supply chain, supports on-demand ordering, responses to multiple varieties and small batches rapidly, and achieves a win-win situation among online, offline retailing and logistics 
under the collaboration of the network.

2.2.5 New retailing requires companies to be customer-centric

In the industrial era, customer-centricity was just a slogan. At present, it is the goal and the highest state that everyone is pursuing. The enterprise-centric business pattern is changed to the consumer-centric era. In the future, everything will be consumer-and-customer-centric.

In a word, due to the development and evolution of traditional retailing over the years, operational efficiency has come to an end, even if the information system is developed, there is no way to make a big breakthrough through its own efforts.

\section{Reasons or Motive Force for Developing "New Retailing"}

3.1 Disappearance of online bonus

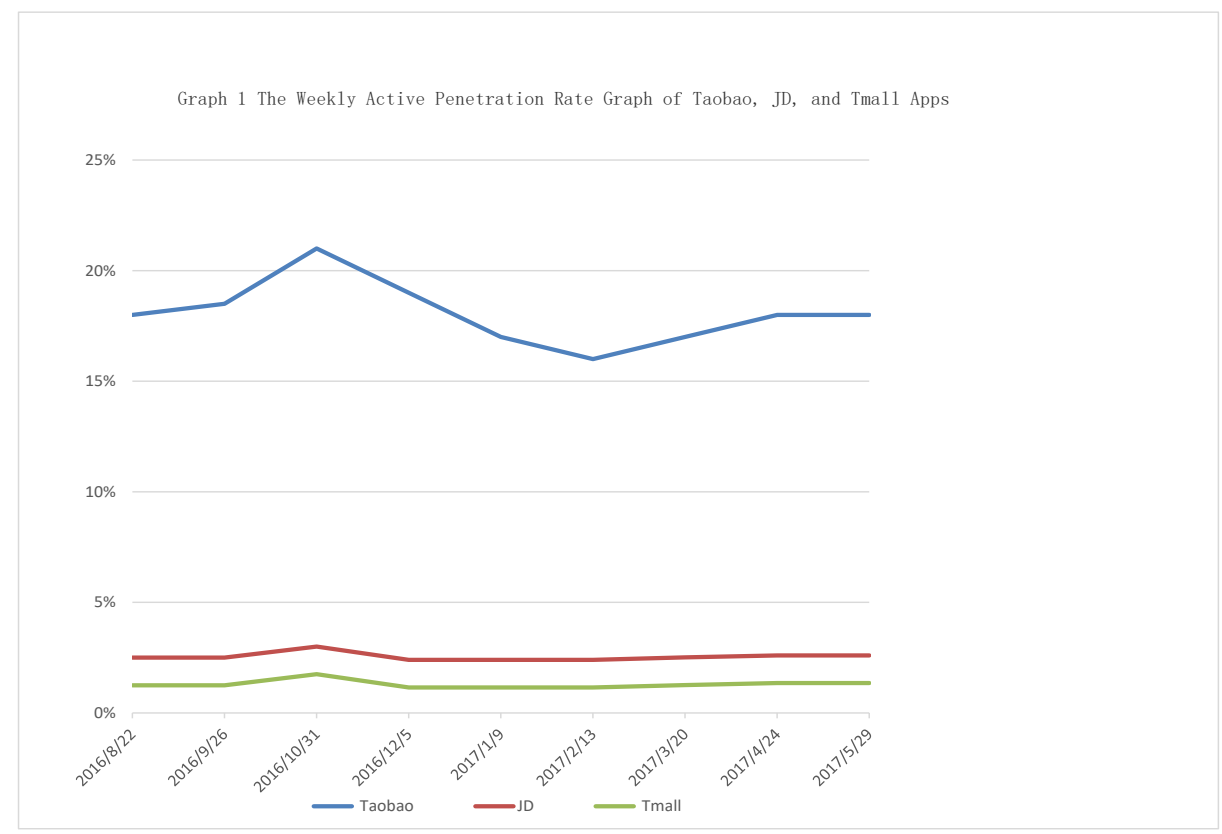

Fig 2. The Weekly Active Peneration Rate Graph of Taobao, JD, and Tmall APPs

Since the online retailing emerged in China, it has once been sought after by people due to its flexible operating methods and fast payment methods. However, after the rapid development period from 2008 to 2012 , the widespread popularity of the Internet and mobile Internet terminals has led to gradual shrinking of user growth and the flow dividends. Coupled with the inherent deficiencies of online retailing, such as lack of user experience, the "ceiling" of its development has begun to appear. In recent years, the total online transaction volume all over the country seems to keep increasing, but the growth rate is declining year after year. According to data from the National Bureau of Statistics: from January to September in 2014, national online retailing sales reached CNY1, 823.8 billion, up by $49.9 \%$ year-on-year; from January to September in 2015 , national online retailing sales reached CNY2591.4 billion, up by 36.2\% year-on-year; From January to September in 2016, national online retailing sales reached $\mathrm{CNY} 3,465.1$ billion, up by $26.1 \%$ year-on-year. E-commerce has experienced more than ten years of development. Thus, the structure will not change significantly. According to Libra's weekly active penetration rate ranking on Chinese e-commerce apps [5], mature online shopping platforms such as Taobao and Tmall have accounted for more than $70 \%$ of the market share, and their head advantage is very obvious (see Graph 1). Libra also provided the weekly active penetration rate and new installation rate data of Taobao, JD, and Tmall apps from August 22, 2016 to June 18, 2017 (see Fig 2). As seen from the graph, the overall trend is flat, and only 
one significant increase occurred during the Double 11 shopping carnival period. If online retailing wants to continue to occupy the transaction volume of the retailing industry, it must open up the offline market to seek further development. Ensuring that goods can be delivered within half an hour plays a key role in offline retailing. According to data from Alibaba, Ali's e-commerce transaction volume reached about 3 trillion in 2017, of which the transaction volume in the short delivery cycle was only about 200 billion. It can be seen that there is still a lot of room in the retailing field in short delivery cycle, and such a wide disparity in turnover is also an important motive force for the development of "new retailing".

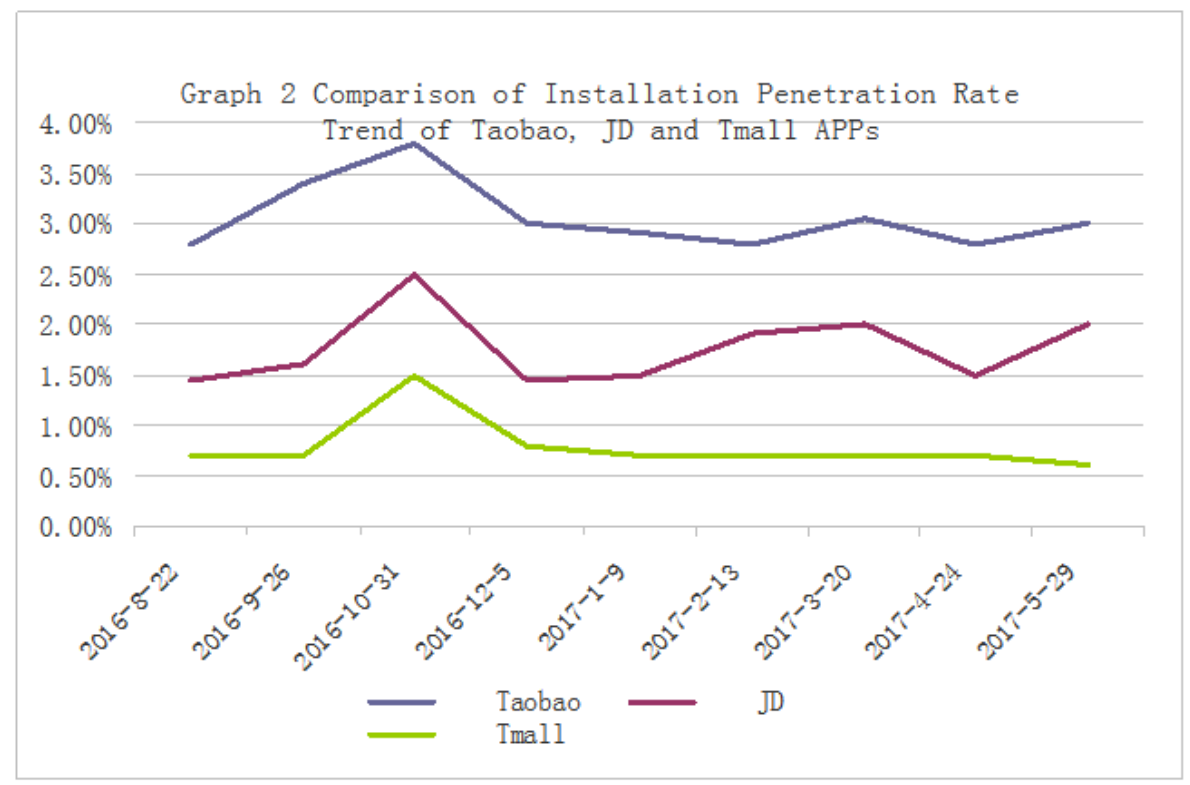

Fig 3. Comparison of Installation Peneration Rate Trend of Taobao, JD, and Tmall APPs

\subsection{The hard time of offline retailing}

Online retailing is in decline, and offline retailing is having a hard time too. Offline retailing generally suffers from deficiencies such as single product categories, inflexible purchasing methods and purchasing time, and higher price than that online. With the advent of the Internet era and the change of people's shopping concepts, a large number of consumers are attracted by online shopping so that online retailing is constantly squeezing and penetrating into offline retailing. In addition, offline retail itself is restricted by cost factors such as store rents, employee salaries, utility bills, etc., and is hard to survive. In only three years from 2012 to 2015, the retail sales growth rate of China's 100 key large-scale retail companies dropped from $10.8 \%$ to $-0.1 \%$. Large-scale supermarkets and specialty stores all over the country closed frequently. Many brick-and-mortar retailers have moved online to find a way out. At this time, the online shopping market can be described as a mixed bag, with a variety of defective products and fakes emerging in an endless stream, which also has a negative impact on online retailing.

In short, in 2017, the growth of online retailing was weak, and the floe dividend was about to dry up. Offline retailing could not bear the pressure of fixed costs. Both of them urgently need to change the traditional operating mode. Online and offline retailing are bound to reconcile and develop together. For this reason, the combination of the two to start new retailing is the only way out (see Fig 3).

\section{Current Status of Sporting Goods Companies' Product Sales}

4.1 Sporting goods companies' experience of sales transiting from entities to e-commerce

Products of sporting goods companies are firstly sold to terminal dealers, which sell products according to the outdated mode. In 2008, after the economic crisis, the market was depressed. In order to promote product sales, each store is keen to hold various promotional activities. Before store anniversaries and holidays, every store

ISSN: 0010-8189 
manager worked hard to plan promotional activities carefully, set up decoration for stores, recruited temporary workers to distribute flyers, and attracted customers for physical marketing. Since usually no one cares about the product, doing this kind of marketing is like a shot in the arm. Once you do it, you will get a wave of popularity. After the event, it will return to the original state and no one cares.

In recent years, e-commerce platforms have emerged, Internet sales have become more and more obvious, and the sales channels and marketing methods of sporting goods have also been greatly changed. On the 2016 "Double 11" shopping carnival, major brands such as Nike, Adidas, Li Ning, Anta, etc., had a product transaction volume of more than CNY100 million, which improved the performance of e-commerce at various levels. It shows that online sales bring huge profits to enterprises. While offline retailing is having a hard time. Traditional retail has plummeted, and gross profit and flow have been taken away about $20 \%$ by online e-commerce. In the field of standard commodities, e-commerce's taking away $20 \%$ of the share is almost to an end. To achieve higher growth, they must turn to offline retailing.

In 2016, Jack Ma proposed at the Hangzhou Yunqi Conference that the era of pure e-commerce has passed, and the new direction is a "new retailing" mode centered on user experience, namely online + offline + logistics.

\subsection{Sporting goods companies' sales entering into "new retailing"}

Since the overall "new retailing" mode is still in its infancy, only a few top sporting goods companies have entered the new retailing business. For example, Nike and 361 enter Tmall to integrate online and offline business and share omni-channel inventory; Adidas and Xtep cooperate with Alibaba to enter Ali stores and try face scan payment, AR, VR scene technologies, etc., to truly realize smart shopping guides and smart transactions, help consumers understand consumption needs and provide them with more precise consumption guidance.

4.2.1 Significant sales profit increase of nike after entering tmall smart store

On November 8, 2017, Nike closely followed the pace of the era and took the lead in approaching the "new retailing" mode. It officially announced its access to Tmall Smart Store. Nike's two branch stores in Beijing and Hangzhou were the first to open for orders, and tested the digitalization of passenger flow. At the same time, Nike's 50 direct-sale stores participated in the online orders with offline delivery on Double 11 Shopping Carnival. At this point, the international retailing giant Nike has officially embarked on the new retailing road.

In the Double 11 Shopping Carnival activity in 2017, Nike's turnover of CNY600 million throughout the day not only ranked No. 1 in Tmall apparel, but also became the best-selling brand in the United States that day. According to the latest financial report released by Nike [6]: The annual operating income increased by $5.3 \%$ to USD8.68 billion, and the result exceeded Wall Street's expectations. This financial report specifically pointed out that Tmall cooperated with Nike to officially enter the "new retailing" mode, and it is expected that the "new retailing" mode sales will boost profits per share by about $15 \%$ in the next five years. In addition, in the "new retailing" era, Nike hopes to combine online and offline advantages, implement an omni-channel marketing mode, and explore the development path of new retailing.

4.2.2 Adidas emphasizing on consumers' experience in offline stores

There is a customer personalized customization center in the Adidas store. Customers can have one-to-one communication with Adidas product experts. Each customer can consult for up to one hour. Customers can fully understand product information at any time. Customers can also collaborate with local artists through wireless communication to design and customize special patterns for their own shoes and apparel products. Through emotional communication with customers, sensory and rational experience must bring certain effects to customers and increase product sales rate. The setting of the personalized experience hall provides consumers with a better personalized experience, and its business strategy has exceeded the meaning of general product sales.

\section{Existing Problems of "New Retailing" Mode}

ISSN: 0010-8189

(C) CONVERTER 2020

www.converter-magazine.info 
5.1 Full of "futuristic" and "scientific sense" in "new retailing" mode making it expensive and difficult to replicate

The settlement door of Nike stores is generally composed of two tunnel-like doors. After entering the first door, the door will automatically close. The sensor on the pillar will identify the user's goods, and then use the radio frequency identification device (RFID) to identify the consumer's information to finish the payment. Because the recognition technology has a strong sense of technology with high costs, it cannot be copied by ordinary stores, and there is still a long way to go before commercialization.

\subsection{Immature recognition technology making it difficult to recognize accurately in a complex environment}

Due to the high requirements of computer recognition technology, it is difficult to perform accurate recognition in places with a large number of people, especially in front of shelves with dense passenger flow. Particularly, complex operations such as goods that are picked up and placed elsewhere, it is difficult for computer vision to accurately identify them.

\subsection{Data-driven operation a development bottleneck}

"New retail" is the combination of online and offline retailing, and offline retailing stores are an important link in the integration with consumers. This contact is based on data and is an optimization of the entire chain. Whether it is warehousing logistics, or the flow entrance with imagination space, it is driven by data. Therefore, data-based operations are an important link in the development of "new retailing" and the key to the success or failure of "new retailing" operations. If there is no experience based on data, it is like water without a source. Because without data analysis, it is difficult to predict the possible consumer willingness to increase product sales [7].

\subsection{Lacking professional and technical personnel in "new retailing" mode}

At present, technologies that can be used in the "new retailing" mode mainly include QR code scanning, radio frequency identification device (RFID), product movement track recognition, face and product image recognition, etc. However, no matter which technology is put into actual operation, unexpected problems will appear and require professional and technical personnel to solve them. Therefore, whether it is new retailing or old retailing, manned or unmanned retailing, the investment ratio of new technical talents will become the core competitiveness of the industry.

\subsection{Big difference between online and offline prices}

The online and offline prices of the same product are not the same. E-commerce shows the price to the public online, which has a great impact on the sales of the product. Even if products are the same, their prices are different from different merchants. As consumers can't see the actual product, merchants that sell products at a lower price are more likely to gain advantages. The lower the price, the less profits merchants will make, which will easily lead to low-price vicious competition, and it is not good for the sales and development of corporate products.

\section{Opportunities and Challenges of Sporting Goods Companies' Implementing “New Retailing”}

In recent years, after the baptism of Internet e-commerce, sporting goods companies have gradually joined online sales, such as Li Ning, Nike, Adidas, Anta, 361 and other companies. They cooperated with Tmall, JD, Suning to carry out online sales and build their own mobile studios, APPs and malls. Powerful companies also build their own logistics. Therefore, sporting goods companies' understanding of "new retailing" keep up with times.

\subsection{Opportunities of sporting goods companies' implementing "new retailing"}

6.1.1 Sporting goods companies facing opportunities in new business formats

ISSN: 0010-8189

(C) CONVERTER 2020 
Sporting goods industry, like traditional retail companies, has gone through the route of wholesale, branding, shopping malls, and monopoly; e-commerce companies have also gone through Taobao, JD, and Vipshop that focuses on market segmentation. Both online and offline companies have experienced these stages, which indicates that focusing on market segmentation is the demand of the era.

In 2016, after Jack Ma proposed the concept "New Retailing", various industries quickly deployed and raced to create an unprecedented grand occasion. Like Nike's entry into Tmall, Adidas's cooperation with Ali, etc., the fundamental reason is that online and offline companies have reached the point where they must work together. Only through cooperation can they achieve a win-win situation and survive. In the period of a round of transformation and the reshuffle of the stores, the advantages of the giants under the new mode are not obvious. If the sporting goods companies seize this opportunity, it is possible to achieve corner overtaking!

\subsubsection{Sporting goods companies facing new consumption opportunities}

Through the exploration of new retail ING, we found that new retailing is about grasping the needs of consumers, infinitely approaching their inner needs, reconstructing main factors such as people, goods, and markets, and realizing a consumer-centric experience.

Compared with other enterprises, the way that sporting goods enterprises contact with consumers is more direct. For example, in terms of consumption habits, consumers mostly shopped in shopping malls and specialty stores in the past, while consumers' consumption patterns are fragmented and consumption habits have undergone major changes at present. For this reason, powerful sporting goods companies' cooperation with online smart stores to enter the "new retailing" mode can contact consumers easily to master their consumption habits. In terms of consumption scenes, they were relatively single and there was no advantage at all in the past. But now powerful sporting goods companies, with the help of online smart stores, can use "big data" to achieve precise procurement and stocking, and reduce corporate costs [8].

In short, "new retailing" mode has a very optimistic prospect. Managers of sporting goods companies should start from their own business goals and capabilities to seize this opportunity, improve consumer experience, and look forward to the emergence of more high-quality companies in this field.

\subsection{Challenges of sporting goods companies' implementing "new retailing"}

The advent of the new era brings more challenges than opportunities. Sporting goods companies, like other companies, must face the pain of transformation. It will bring changes in the production, sales and consumption systems. It is not a denial and abandonment of the traditional retail system, but to complement their advantages.

6.2.1 Sporting goods companies facing the challenge of channel integration

If sporting goods companies want to participate in "new retailing", they must follow the path of online and offline integration, mutual shareholding and strategic cooperation, to achieve omni-channel integration. At the same time, they need to not only cultivate insight into people, goods, and markets, but also strengthen the ability to cultivate and build their own data.

6.2.2 Changes in business logic after sporting goods companies intervening in the "new retailing" mode The process of "new retailing" is that enterprises and consumers create demands together, and in which the products should meet the common demands of enterprises and consumers. But this business logic of co-creating consumer demand is a challenge for sporting goods companies. First, at present, the hardware conditions of sporting goods companies are still difficult to create experience together with consumers and change consumer's role as an onlooker, and there is still a long way to go before the establishment of co-creating demand with consumers. Second, in this information age, most consumers make rational and scientific consumption decisions by referring to "big data" information, rather than being limited by small-scale and one-sided information around them. At present, sporting goods companies still lack this powerful resource linking ability, which can maximize 
consumer demand and influence consumer decision-making.

6.2.3 Great changes in market environment and transaction subject after sporting goods companies intervening in the "new retailing" mode

With the continuous development of the "new retailing" mode, the market environment will continue to change. The sales of sporting goods companies will transit to a pan-retail format, and many new business formats will appear such as wechat business, various physical retail, etc., and consumers can even pass the retailer to directly contact the factory to form a state of customized retail.

From the perspective of transaction subjects, retail is no longer the privilege of enterprises or individuals. In the future, anyone can become a retailer, and retail will become more popular. From the perspective of transaction objects, in the future, both goods and services will be given value and become transaction objects and they will no longer be constrained by the form of ownership. From the perspective of trading space, whether online or offline, retail in any scenario is likely to appear. Retail is developing to be scene-oriented, and its trading space is greatly expanded.

In short, the "new retailing" sales mode is developing rapidly. Sporting goods companies should grasp the current situation as soon as possible, be early for market, and use the "new retailing" mode to stimulate their development motive force. In addition, sporting goods companies should also develop electronic payment and professional payment data mining and analysis services that meet the needs of the era, so as to be early for market and occupy a broader market.

\section{Suggestions and Countermeasures}

\subsection{Suggestions of sporting goods companies' implementing "new retailing"}

7.1.1 Sporting goods companies focus on improving user experience when layout "new retailing" With the development of society and the improvement of people's living standards, people's consumption habits and structure are constantly changing. In order to stimulate consumption and upgrade retail mode, it is necessary to adopt an online and offline integration mode to truly achieve integrated operations, and transform to be sharing, scene-oriented, quality-oriented, entertainment-oriented, customized, personalized, etc. And it is necessary to commit to the research and development of the smart retail field, achieve comprehensive online and offline interoperability, integrate advanced supply chain management, technical support, and big data analysis to build a smart cloud system platform that can achieve precise and refined operations, realize the reconstruction of people, goods and fields, provide easy and integrated solutions for the sales and retail industry, and help the overall upgrade of retail channels.

7.1.2 Sporting goods companies that want to deploy smart "new retailing" must have strong smart data service capabilities as a guarantee

Online retail has inherent advantages in data acquisition and analysis, but it is now facing the dilemma of the exhaustion of flow dividends. While the supply chain system of offline retail is too old and requires advanced and efficient Internet technology to promote its transformation. Only through data integration, multi-dimensional and multi-level analysis of the market can it provide big data support for the daily business and macro insights of retailing enterprises.

7.1.3 Sporting goods companies that want to deploy "new retailing" must find out methods and tools to obtain customers and realize the monetization of flow [9]

Compared with big data, the application of "small data" acquired by enterprises on their own will often produce greater effects in marketing. "Small data" refers to the enterprise's user data, sales data, service data, etc. Using these data will definitely bring new opportunities for enterprise marketing. The "small data" marketing system of new retailing includes collection, sorting, matching, and fusion, which requires the construction of a data collection platform and process, that is, exposure, clicks, registration, shop visits, and order signing. After undergoing the

ISSN: 0010-8189 
transformation of marketing "separation", "grading" and "grouping", mobilization has given smart terminal technology a new role. Through the diversified retailing data, consumers' life experience will be improved. Future new retailing must be on the road to perfect products and respect consumers.

7.1.4 Adapting the "unmanned" link in the "New Retailing" mode to local conditions based on cost

"New Retailing" is full of technological sense, and its related technologies include a lot of big data and algorithms, whose costs are expensive. For this reason, with the current relatively low personnel costs, companies do not need to increase cost input in pursuit of a "sense of science and technology" regardless of the cost-benefit ratio. Only when big data and "sense of science and technology" accumulated to a certain extent, "unmanned" sales can give full play to its advantages and improve its efficiency in aspect like goods selection, logistics, and shipment.

\subsection{Countermeasures of sporting goods companies' implementing “new retailing”}

Sporting goods companies must emancipate their minds if they want to deploy "new retailing". The development of the era has reached an important period of change, Old traditional thinking is not in line with trend development. Therefore, we must clearly realize that if companies want to deploy "new retailing", they must break the old thinking framework, embrace new ideas, adapt to new needs, and take the initiative to transform. Cooperation leads to a win-win situation. Only by seizing the opportunity can companies achieve corner overtaking!

\subsubsection{Simpler platform for the layout of "new retailing" mode}

The essence of "new retailing" should be that everyone who wants to participate can participate without high threshold requirements. If people want to participate, they just need to register on JD.com, Xiaomi or Taobao. Since each provider provides different services, people can choose one according to their needs. For example, if you choose Taobao, after registration, you will immediately see all the addresses of Taobao Digital stores in your city with different prices displayed, you can choose one directly. After you complete all the registration procedures, the store will be officially opened. At the same time, you will be connected to the large platform of Taobao offline stores. When you purchase storefront services on the large platform, Taobao will come to decorate the store. If you have enough money, you can also buy its logistics or directly buy the flow of Taobao offline store platform, so that your storefront advertising information will display in all the other Taobao offline stores [10].

7.2.3 Relying on big data to realize the digitalization of retail ports if sporting goods companies want to deploy "new retailing"

"New retailing" is a necessity built on the Internet. This kind of necessity generates big data. Through data classification and analysis, consumers' different needs can be found. Certainly, the acquisition of data requires the popularization of modern technology and the application of big data.

Under the "new retailing" mode, whether it is online or offline, as long as its consumer behavior is real, the existing technology can not only turn it into real data, but also deposit the data of every customer and every transaction, and guide marketing and sales through the demand. It is timely and accurate in directing production and optimizing the supply chain through the supply.

7.2.4 Sporting goods companies must decouple a series of relationships to truly achieve omni-channel integration Therefore, companies must reconstruct customer relationships, consumer perceptions, partner relationships, and internal relationships within the organization. Using big data, through panoramic analysis, to predict consumer buying behavior and match interest products. Finally, ordering online and channeling offline to complete the last of sales.

7.2.5 Sporting goods companies needing "Decentralization" and cost performance improvement of products Companies can use the Internet to make their sports product information more transparent, "optimize" and "simplify" the channel links of the original value in the traditional channel mode, generate everyone's link value, and complete products' sales collaboration. In the end, it not only makes the goods and services traded more 
"cost-effective", but also maximizes the income-utility ratio of the participants.

7.2.6 Sporting goods companies' layout of "New Retailing” needing decision making by machine as much as possible

With the development of the Internet, enterprises should build smart stores as much as possible for the "new retailing" layout, use big data analysis technology, and make corresponding pre-sales plans based on user demand information to transform those dispensable consumer needs into specific market consumption. If this transformation occurs frequently, it will stimulate the growth of the consumption market.

\section{Conclusion}

The rapid development of technology has brought not only beauty to the era, but also subversion. Retailing is certainly not the only fortress washed away by the wave of technology. More industries are receiving the baptism of the Internet. Change is the only constant truth in this era. Of course, the transition is painful because none of us knows where the way is. Learn and know, think, summarize past judgments and dream about the emergence of the future. "New retailing", new industries, and new dreams need us to lay out, practice, and explore. Let's make this newcomer more unique!

\section{References}

[1] "Opinions of the general office of the state council of the people's republic of china on promoting the innovation and transformation of physical retailing," GBF, no. 78, 2016, http://www.gov.cn/zhengce/content/2016-11/11/content_5131161.htm.

[2] F. Xiao, "What is new retailing? Which points do we need to pay attention to?" http://dy.163.com/v2/article/detail/D0Q2CHN00518NUR1.html.

[3] Anonymous, "Future development and effort direction of New retailing," http://www.pc6.com/edu/140890.html

[4] K. Qu, "Investment logic of New retailing," https://www.huxiu.com/article/188817.html?rec=manual

[5] G.L. Cheetah, "New retailing is the result of the reconciliation of e-commerce and traditional retail," http://www.199it.com/archives/526104.html

[6] F. Lu, "Nike access to tmall smart stores on double 11 shopping carnival, the deep meaning of international giants embracing new retailing," https://www.sohu.com/a/203387015_102905

[7] B.M. Feng, "How to implement self-service retail technology, the technology is not mature actually," https://www.hishop.com.cn/xls/show_44119.html

[8] F. Li, "What opportunities and challenges are faced by direct selling companies' new retailing?"

[9] K. Liu, "How do traditional retail companies deploy new retailing? what development opportunities do they bring to companies,"

[10] J.H. Bai, "Platformization is the general trend of new retailing in the future,"

[11] http://baijiahao.baidu.com/s?id=1574732342996956\&wfr=spider\&for=pc 